JURNAL ILMIAH ELEKTRONIKA DAN KOMPUTER, Vol.14, No.2, Desember 2021, pp. 261 - 267

p-ISSN : 1907-0012 (print)

e-ISSN : 2714-5417 (online)

http://journal.stekom.ac.id/index.php/elkom

\title{
Prediction Of Medical Actions For Covid Patients Using Naïve Bayes Method
}

\author{
Arfan Haqiqi ${ }^{1}$, Rais $^{2}$, Istiqomah Dwi Andari ${ }^{3}$, Siti Fatimah ${ }^{4}$ \\ ${ }^{1}$ Program Studi DIII Teknik Komputer, Politeknik Harapan bersama \\ Jl. Mataram No. 09, Pesurungan Lor, Kec. Margadana, Kota Tegal, Indonesia 52142 \\ e-mail : Arfan.hqq@gmail.com \\ ${ }^{2}$ Program Studi DIII Teknik Komputer, Politeknik Harapan bersama \\ Jl. Mataram No. 09, Pesurungan Lor, Kec. Margadana, Kota Tegal, Indonesia 52142 \\ e-mail : rais@poltektegal.ac.id \\ ${ }^{3}$ Program Studi DIII Kebidanan, Politeknik Harapan bersama \\ Jl. Mataram No. 09, Pesurungan Lor, Kec. Margadana, Kota Tegal, Indonesia 52142 \\ e-mail : istyandari44@gmail.com \\ ${ }^{4}$ Program Studi DIII Kebidanan, STIKES BREBES \\ Jl. Jatibarang KM 8 Janegara Kec. Jatibarang Kab. Brebes, Indonesia 52261 \\ e-mail : helga.abhinaya@gmail.com
}

\section{ARTICLE INFO}

Article history:

Received 12 Oktober 2021

Received in revised form 14 Oktober 2021

Accepted 16 Oktober 2021

Available online 1 Desember 2021

\section{ABSTRACT}

Management of medical actions carried out in handling patients who are ODP (people under monitoring), OTG (asymptomatic people), PDP (patient under monitoring) and positive Covid-19 patients is carried out based on assumptions, such as self-isolation, hospitalization, or special treatments in the ICU (Intensive Care Unit) room. The condition of the body in each patient is different, a patient may have same symptoms but the treatment is different, especially in elderly patients. Many problems occur in determining medical action because the patient's body condition is different. Therefore, it needs to be appointed as a research. The research method used in this study was Nive Bayes algorithm with supporting application Rapid Miner. It was applied to carry out the process of testing on patient data as much as 500 data, 25 variables or patient symptoms and 3 outputs as a form of medical action. Based on the results of the analysis carried out in this study, prediction of medical actions for ODP, PDP, OTG and positive Covid-19 patients were obtained by comparing training data with testing data using Rapid Miner application. It resulted that an accuracy rate of $76.00 \%$ was obtained.

Keywords: Pasien, Covid-19, Nä̈ve Bayes, Prdiksi 


\section{Introduction}

COVID-19 adalah penyakit yang menular, dan ditandai oleh gejala pada bagian pernapasan akut (coronavirus 2 (severe acute respiratory syndrome coronavirus 2 atau SARS-CoV-2) [1]. Penyakit Coronavirus (COVID-19) telah meresahkan dunia khususnya Indoesia sebagai bencana non alamiah berupa [2]. Covid-19 telah ditetapkan sebagai pandemi global oleh WHO karena tingkat penyebarannya yang begitu cepat antar manusia. [3]. Penyebaran kasus COVID-19 yang terjadi secara cepat di 188 Negara [4]. Data terbaru World Health Organization mengenai COVID-19 secara global melaporkan bahwa sampai dengan tanggal 21 Oktober terdapat 350.424 kasus baru, 40.665.438 penderita dan 1.121.843 meninggal dunia [5][6].Di Indonesia data BNPB berdasarkan data kementrian kesehatan sampai tanggal 21 Oktober 2020 penderita COVID-19 berjumlah 373.102 penderita, kasus aktif sebanyak 62.743 penderita dan meninggal sebanyak 12.857 penderita. Penderita COVID-19 terbanyak berada di DKI Jakarta (97.217 penderita), Jawa Barat (31.907 penderita), Jawa Timur (49.801 Penderita), Jawa Tengah (30.218 penderita), Sulawesi Selatan (17.690 penderita), Riau(12.319 penderita) dan Kalimantan timur (12.221 penderita) [7].

Covid-19 dapat menular ke semua orang yang memiliki kekebalan tubuh lemah. Namun yang paling beresiko terkomplikasi Covid-19 adalah orang yang lanjut usia, menderita penyakit komplikasi atau penyakit kronis. Resiko akan kematian yang disebabkan oleh Covid-19 sangat tinggi, terutama pada lanjut usia, kanker, memiliki diabetes, penyakit jantung, pembekuan darah atau yang telah menunjukan tanda-tanda sepesis. Dengan tingkat kematian rata-rata $1 \%$, tingkat kematian meningkat menjadi $6 \%$ pada orang dengan kanker, menderita hipertensi, atau penyakit pernapasan kronis, $7 \%$ untuk penderita diabetes, dan $10 \%$ pada penderita penyakit jantung. Sementara tingkat kematian di antara orang berusia 80 atau lebih berisiko 15\% lebih tinggi [8].

Manajemen tindakan medis yang dilakukan dalam penanganan pasien yang ODP, OTG, PDP serta sudah positif Covid-19 dilakukan berdasarkan asumsi saja, misalya isolasi mandiri, rawat inap, atau dengan tindakan khusus di ICU. Kondisi tubuh pada setiap pasien berbeda-beda bias jadi pasien dengan gejala yang sama namun penangananya berbeda apa lagi pada pasien yang sudah lanjut usia.

Berangkat dari permasalahan diatas, maka peneliti tertarik untuk melakukan klasifikasi prediksi guna mendapatkan informasi yang digunakan untuk memberikan rekomendasi kepada petugas kesehatan dalam memberikan tindakan yang tepat kepada pasien OTG, PDP, ODP atau yang dinyatakan positif Covid-19 berdasarkan usia. Sehingga nantinya tindakan yang diberikan akurat dan pasti.

Metode penelitian yang digunakan adalah klasifikasi dan prediksi. Banyak metode yang dapat digunakan diantaranya Regresi Logistik, neural network, K-nearest Neighboor, Super Vector Machine, Naive Bayes, Decision Tree dan Random Forest [9]. Namu pada penelitian kali ini akan menggunakan metode Nä̈ve Bayes.

Klasifikasi adalah teknik yang dilakukan untuk memprediksi class atau properti dari setiap instance data. Model prediksi memungkinkan untuk memprediksi nilai-nilai variabel yang tidak diketahui berdasarkan nilai variabel lainnya. Klasifikasi memetakan data ke dalam kelompokkelompok kelas yang telah ditetapkan sebelumnya. Klasifikasi disebut juga dengan supervised learning karena kelas data telah ditentukan sebelumnya [10].

Penelitian Naive Bayes terkait penggunaan Nä̈ve Bayes Classifier telah banyak dilakukan. Nä̈ve Bayes memiliki beberapa kelebihan, yaitu cepat dalam perhitungan, algoritma yang sederhana dan berakurasi tinggi dan Nä̈ve Bayes Classifier lebih tepat diterapkan pada data yang besar dan dapat menangani data yang tidak lengkap (missing value) serta kuat terhadap atribut yang tidak relevan dan noise pada data [11].

JURNAL ILMIAH ELEKTRONIKA DAN KOMPUTER Vol. 14, No. 2, Desember 2021: $261-267$ 


\section{Research Method}

\subsection{Bahan Penelitian}

Bahan penelitian yang digunakan adalah data pasien covid yang didapat dari rumah sakit, diantaranya: RSUD Dr. Soesilo, RSUD Suradadi, Rumah Sakit DKT Pagongan, RSI PKU Muhammadiyah, RS Harapan Sehat, RSUD Kardinah, RS Mitra Siaga serta RSUI Harapan Anda untuk data pasien Covid-19.

\subsection{Alat Penelitian}

Adapun alat bantu yang digunakan untuk dalam pengumpulan data penelitian ini adalah menggunakan observasi.

\subsection{Prosedur Penelitian} berikut:

Penelitian ini menggunakan jenis penelitian eksperimen, dengan tahapan penelitian sebagai

1. Pengumpulan Data

Pengumpulan data merupakan langkah awal pada suatu penelitian. Data yang digunakan pada penelitian ini adalah data rekamedik pasien OTG, PDP, ODP dan Positif Covid-19 sepanjang tahun 2020 dan 2021.

2. Pembersih Data

Pada tahap ini akan dilakukan pembersihan data yang tidak lengkap, kosong (null), noise, dan data yang tidak konsisten. Dalam langkah ini, data yang bernilai kosong (null), akan dibersihkan dengan cara dihapus secara manual, dan akan dilakukan penghapusan atribut atau mengganti data tersebut

3. Seleksi Data

Pada tahap ini, akan dilakukan penyelesaian data untuk mengurangi data yang tidak relevan, dan berlebihan (redundant). Menurut Tan, Steinbach, dan Kumar (2006), atribut yang tidak relevan adalah atribut yang berisi informasi yangtidak berguna unutk melakukan penambangan data, sedangkan atribut yang berlebihan (redundant) adalah atribut yang menduplikasikan banyak atau semua informasi yang terdapat di dalam satu atau lebih pada atribut lainnya

4. Pengolahan Awal

Pengolahan awal (Preprocessing) merupakan tahap untuk mempersiapkan data yang telah diperoleh dari tahap pengumpulan data, yang akan digunakan pada tahap selanjutnya.

5. Metode yang Diusulkan

Tahapan ini akan membahas motode yang akan digunakan pada penelitian. Metode yang digunakan adalah Naïve Bayes

6. Eksperimen dan Pengujian

Tahapan ini akan membahas tahapan penelitian dan teknik pengujian yang akan digunakan.

7. Evaluasi dan Validasi Penelitian

Tahapan ini akan membahas hasil evaluasi dari eksperimen yang telah digunakan, menggunakan $K$-Fold Cross Validation.

\section{Results and Analysis}

\subsection{Hasil Eksperimen dan Pengujian Metode}

Untuk mendapatkan model yang sesuai dengan yang diharapkan, pada tahapan eksperimen dilakukan dengan melakukan percobaan dengan Rapid Miner seperti contoh dibawah ini : 

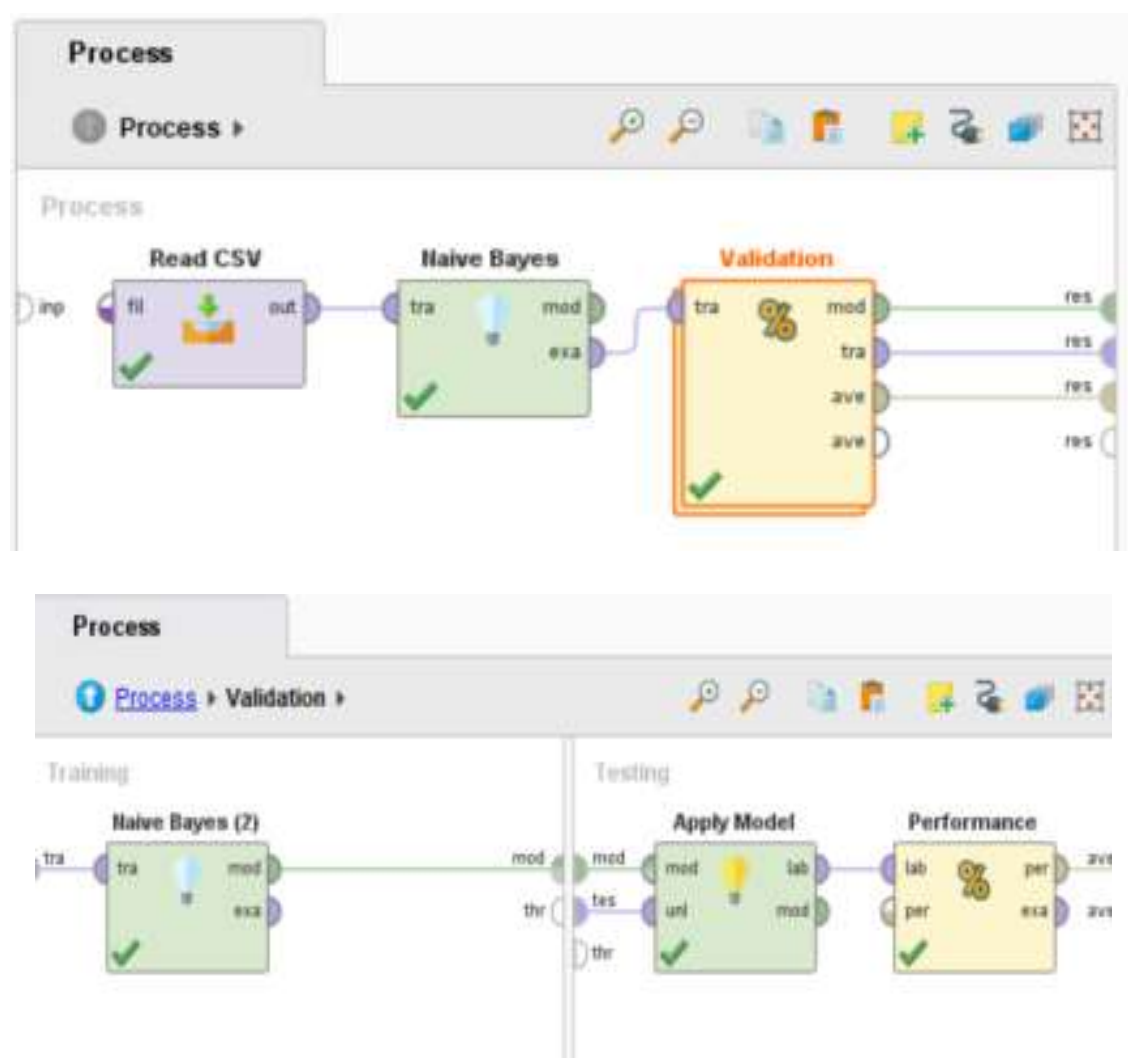

Gambar 1. Proses Rapid Miner

Setalah itu dilakukan pengujian menggunakan tools Rapid Miner, kemudian :

1. Menambahkan dua operator read excel untuk memasukan data training dan data testing

2. Menambahkan operator naive bayes yang digunakan sebagai metode dalam penelitian.

3. Menambahkan operator split validation digunakan untuk proses pengolahan data. Yang didalamnya terdapat operator Nä̈ve Bayes, Apply Model dan Performance untuk mementukan hasil prediksinya.

\subsubsection{Proses Validasi}

Pada tahapan validasi ini menggunkan data responden sebanyak 500 pasien, 25 Variabel input dan 3 output dengan split relative, split ratio dari 0.1-0.9, sampling type automatic didapat hasil seperti tabel dibawah ini :

Tabel 1. hasil proses validasi

\begin{tabular}{|c|l|c|c|c|}
\hline No & Split & Sampling Type & Splite Ratio & Accuracy \\
\hline 1 & relative & automatic & 0.1 & $70.44 \%$ \\
\hline 2 & relative & automatic & 0.2 & $73.50 \%$ \\
\hline 3 & relative & automatic & 0.3 & $73.14 \%$ \\
\hline 4 & relative & automatic & 0.4 & $74.25 \%$ \\
\hline 5 & relative & automatic & 0.5 & $63.60 \%$ \\
\hline 6 & relative & automatic & 0.6 & $73.13 \%$ \\
\hline 7 & relative & automatic & 0.7 & $72.67 \%$ \\
\hline $\mathbf{8}$ & relative & automatic & $\mathbf{0 . 8}$ & $\mathbf{7 6 . 0 0 \%}$ \\
\hline 9 & relative & automatic & 0.9 & $74.00 \%$ \\
\hline
\end{tabular}

Dari bebrapa percobaan yang dilakukan mendapatkan akurasi yang lebih baik adalah $76.00 \%$ dengan split ratio 0.8 dengan bentuk Confusion Matrik seperti dibawah ini :

JURNAL ILMIAH ELEKTRONIKA DAN KOMPUTER Vol. 14, No. 2, Desember 2021: $261-267$ 


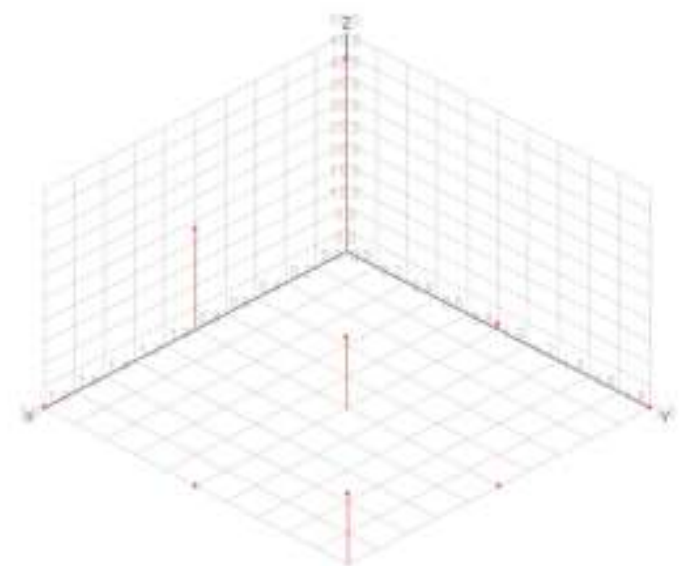

Gambar 2. Confusion Matrik

\subsubsection{Metode Nä̈ve Bayes}

Proses klasifikasi dengan Rapid Miner menggunakan metode Nä̈ve Bayes yang digunakan untuk memprediksi/klasifikasi tindakan pasien sehingga didapat akurasi hasil prediksi $76.00 \%$ dari hasil data testing. Pengujian berdasarkan Confusion Matrix menghasilkan nilai accuracy, precision dan recall yang tinggi dengan nilai accuracy sebesar 76.00\%. dengan Class precision untuk Pred. Isoman 65.67\%, Pred. Isolasi rumah sakit 94.12\%, Pred. ICU 100\% sedangkan Class Recall untuk True Isoman 97.78\%, True. Isolasi rumah sakit 41.03\%, True ICU 100\%. Dengan tabel dibawah ini:

Tabel 2. Class Precision dan Class Recall

\begin{tabular}{|c|c|c|c|c|}
\hline & tue isongn & tue lsolasi numah satt & tue icu & dass prection \\
\hline Brad. isoman & 4 & 2) & 0 & $65.67 \%$ \\
\hline cred laobai numah satil & 1 & 16 & 0 & $9412 \%$ \\
\hline pred kCu & 0 & 0 & it & $16000 \%$ \\
\hline dass recal & ต77a\% & 41.034 & $100.00 \%$ & \\
\hline
\end{tabular}

\subsection{Evaluasi dan Validasi}

Setelah bebrapa kombinasi nilai parameter yang telah didapatkan, maka setelah divalidasi pada model yang telah digunkan maka didapatkan hasil nilai accuracy atau parameter terbaik Tabel 3. Nilai accuracy/parameter Naïve Bayes

\begin{tabular}{|l|l|}
\hline Split Ratio & $=0.8$ \\
\hline accuracy & $=76.00 \%$ \\
\hline
\end{tabular}

\subsection{Proses Pengujian dan Testing}

Pengujian dan testing dilakukan untuk melihat sejauh mana model dari yang dibuat dapat berjalan pada dataset yang dijadikan untuk testing, hasil analisa antara data testing dengan data training pada Rapid Miner dapat dilihat pada Tabel 4.2. Untuk menghitung akurasinya sebagai berikut :

Jumlah data yang di uji $\quad: 500$

Jumlah data yang diprediksi benar "Isoman" : : : 44

Jumlah data yang diprediksi benar "Isolasi rumah sakit" : 16

Jumlah data yang diprediksi benar "ICU" $\quad: 16$

Jumlah data yang diprediksi salah "Isoman" $\quad: 0$

Jumlah data yang diprediksi salah "Isolasi rumah sakit" : 23

Jumlah data yang diprediksi salah "ICU" $\quad: 0$

Prediction Of Medical Actions For Covid Patients Using Naïve Bayes Method (Arfan Haqiqi) 


$$
\begin{aligned}
\text { Akurasi } & =\frac{44+16+16}{44+16+16+1+0+23} \times 100 \% \mathrm{f} \\
& =\frac{76}{100} \times 100 \% \\
& =76,00 \% \\
\text { Eror } \quad & =\frac{23+0+1}{44+16+16+1+0+23} \times 100 \% \mathrm{f} \\
& =\frac{24}{100} \times 100 \% \\
& =24,00 \%
\end{aligned}
$$

Dari perhitungan tersebut disimpulkan bahwa prediksi dengan menggunakan metode Naïve Bayes untuk menentukan tindakan medis pada pasien ODP, PDP, OTG dan Positif Covid-19 menghasilkan tingkat akurasi sebesar $76.00 \%$ dan tingkat eror $24.00 \%$.

\section{Conclusion}

Dari penelitian yang dilakukan mengenai penerapan metode Naive Bayes untuk prediksi tindakan medis pada pasien ODP, PDP, OTG dan Positif Covid-19 dapat disimpulkan bahwa berdasarkan hasil analisis yang dilakukan pada penelitian ini, didapat hasil prediksi tindakan medis pada pasien ODP, PDP, OTG dan Positif Covid-19 dengan membandingkan data training dengan dengan data testing menggunakan aplikasi Rapid Miner didapat tingkat akurasi sebesar $76.00 \%$.

\section{References}

[1] T. Dey and A. Sinha, "Ethnicity and COVID-19 - A commentary on 'World Health Oganization declares global emergency: A review of the 2019 novel coronavirus (COVID19)' (Int J Surg 2020;76:71-6)," Int. J. Surg., vol. 83, no. August, pp. 75-76, 2020, doi: 10.1016/j.ijsu.2020.08.046.

[2] W. Wiguna and D. Riana, "Diagnosis of Coronavirus Disease 2019 (Covid-19) Surveillance Using C4.5 Algorithm," J. Pilar Nusa Mandiri, vol. 16, no. 1, pp. 71-80, 2020, doi: 10.33480/pilar.v16i1.1293.

[3] B. Etikasari, T. D. Puspitasari, A. A. Kurniasari, and L. Perdanasari, "Sistem informasi deteksi dini Covid-19," J. Tek. Elektro dan Komput., vol. 9, no. 2, pp. 101-108, 2020.

[4] L. Wynants et al., "Prediction models for diagnosis and prognosis of covid-19: Systematic review and critical appraisal," $B M J$, vol. 369, 2020, doi: 10.1136/bmj.m1328.

[5] M. Pradana, S. Syahputra, A. Wardhana, B. R. Kartawinata, and C. Wijayangka, "The Effects of Incriminating COVID-19 News on the Returning Indonesians' Anxiety," J. Loss Trauma, vol. 25, no. 8, pp. 1-6, 2020, doi: 10.1080/15325024.2020.1771825.

[6] World Health Organization (WHO) Indonesia, "Coronavirus Disease 2019 (COVID-19) WHO Indonesia Situation Report," Indones. Situat. Reports, vol. 2019, no. April, pp. 1-9, 2020, [Online]. Available: https://www.who.int/indonesia/news/novel-coronavirus/situationreports.

[7] National Disaster Management Agency, "Head of BNPB Decision Letter No. 9A/2020." p. $3,2020$.

[8] N. Anung Ahadi Pradana , Casman, "Pengaruh kebijakan," Pengaruh Kebijak. Soc. Distancing Pada Wabah Covid-19 Terhadap Kelompok Rentan Di Indones., vol. 09, no. 02, pp. 61-67, 2020.

[9] F. Sodik, B. Dwi, and I. Kharisudin, "Perbandingan Metode Klasifikasi Supervised Learning pada Data Bank Customers Menggunakan Python," vol. 3, pp. 689-694, 2020.

JURNAL ILMIAH ELEKTRONIKA DAN KOMPUTER Vol. 14, No. 2, Desember 2021: $261-267$ 
[10] M. Informatika and K. B. Aceh, "ANALISIS TREND TOPIK PENELITIAN PADA WEB OF SCIENCE DAN SINTA UNTUK PENENTUAN TEMA," pp. 13-25, 2018.

[11] T. Praningki and I. Budi, "Sistem Prediksi Penyakit Kanker Serviks Menggunakan CART, Naive Bayes, dan k-NN," Creat. Inf. Technol. J., vol. 4, no. 2, p. 83, 2018, doi: 10.24076/citec.2017v4i2.100. 